\title{
Correction to: Aggregates, Formational Emergence, and the Focus on Practice in Stone Artifact Archaeology
}

\section{Zeljko Rezek ${ }^{1,2}$ - Simon J. Holdaway ${ }^{3}$ - Deborah I. Olszewski ${ }^{4}$ Sam C. Lin ${ }^{5,6}$. Matthew Douglass ${ }^{7} \cdot$ Shannon P. McPherron ${ }^{1} \cdot$ Radu lovita $^{8,9}$. David R. Braun ${ }^{1,10,11}$ - Dennis Sandgathe ${ }^{12}$}

Published online: 24 February 2020

(C) Springer Science+Business Media, LLC, part of Springer Nature 2020

\section{Correction to: Journal of Archaeological Method and Theory (2020) https://doi.org/10.1007/s10816-020-09445-y}

The original version of this article unfortunately contained mistake in the presentation of the author's name.

Shannon McPherron should be Shannon P. McPherron.

The online version of the original article can be found at https://doi.org/10.1007/s10816-020-09445-y

\section{Zeljko Rezek}

zeljko_rezek@eva.mpg.de

1 Department of Human Evolution, Max Planck Institute for Evolutionary Anthropology, 04103 Leipzig, Germany

2 University of Pennsylvania Museum of Archaeology and Anthropology, Philadelphia, PA 19104, USA

3 School of Social Sciences, University of Auckland, Auckland 1142, New Zealand

4 Department of Anthropology, University of Pennsylvania, Philadelphia, PA 19104, USA

5 Centre for Archaeological Science, School of Earth and Environmental Sciences and Australian Research Council Centre of Excellence for Australian Biodiversity and Heritage, University of Wollongong, Wollongong, NSW 2522, Australia

6 Australian Research Council Centre of Excellence for Australian Biodiversity and Heritage, University of Wollongong, Wollongong, NSW 2522, Australia

7 Department of Anthropology, University of Nebraska-Lincoln, Lincoln 68588, USA

8 Department of Anthropology and Center for the Study of Human Origins, New York University, New York, NY 10003, USA

9 Department of Early Prehistory and Quaternary Ecology, University of Tübingen, 72070 Tübingen, Germany

10 Department of Anthropology, George Washington University, Washington, D.C. 20052, USA

11 Archaeology Department, University of Cape Town, Rondebosch 7701, South Africa

12 Department of Anthropology, Simon Fraser University, Burnaby, BC V5A 1S6, Canada 